International Conference on Research in Education, Teaching and Learning

Paris, France| November 2-4, 2018

\title{
Voluntary Disclosure in UK Higher Education
}

\author{
A. Merika, I. Kapareliotis and A. Triantafyllou
}

Department of Accounting, Economics and Finance, School of Business and Economics, Deree - The American College of Greece

Department of Marketing, School of Business and Economics, Deree - The American College of Greece

\begin{abstract}
Following adoption of the Teaching Excellence Framework (TEF) by the British government, awards of Gold, Silver, and Bronze ratings to UK universities that satisfied TEF criteria were announced in June 2017. We categorize UK universities in five buckets on the basis of their ranking and investigate whether top ranked schools are least likely to disclose their rankings on their websites. Furthermore, we test whether Guardian university rankings are consistent and informative about the TEF medals awarded. Our finding that the higher the ranking of the university the less the likelihood to disclose the TEF result on the university's website is consistent with prior literature. We assert that universities that have a higher rank use nondisclosure as a countersignal, while universities that have a middle rank use disclosure to stand out from the other middle rank universities. Moreover, we find that the probability of UK universities to get a TEF Gold is significantly lower than that of the top-10 and that probability falls substantially in lower ranking buckets. Finally, even though Guardian rankings appear to be generally consistent with and supportive of TEF ratings, only $35 \%$ of the top-ranked universities by The Guardian are rated TEF Gold, indicating discrepancy between Guardian rankings and public national TEF classifications, thereby rendering further investigation of the Guardian ranking - TEF rating relationship necessary, in order to enhance the usefulness of rankings for student consumers.
\end{abstract}

\section{Introduction}

Data compiled by the UK Higher Education Statistics Agency (HESA, www.hesa.ac.uk) indicates that, after a slight fall in 2011-13, both national and international participation in UK higher education has been steadily increasing. HESA's official student enrollment data for 2016/17 shows an increase in the number of students in higher education, a decline in part-time students, and over a quarter of first degree graduates gaining a first. As a result, affording mass higher education and allocating public funds to universities becomes increasingly challenging. In this context, the UK government decided to create a link between funding and teaching quality.

The UK Teaching Excellence Framework was established aiming to "provide clear information to students about where the best provision can be found" (TEF, 2016). 


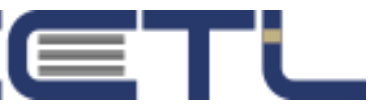

International Conference on Research in Education, Teaching and Learning

Paris, France| November 2-4, 2018

TEF comprises three core pillars, namely students' views on the quality of teaching, learning environment and student outcomes and learning gain (TEF, 2016).

Universities are assessed by an independent panel of experts including academics, students and employer representatives. Universities receive a positive or negative flag if they are above or below a benchmark based on the profile of their student cohort, with the overall number of flags giving an rating as follows: gold for those with three or more positive flags (either single or double) but no negative flags; bronze for those with two or more negative flags (regardless of other results) and silver for the rest. Initial ratings are adjusted according to characteristics of the university's student body, such as gender, ethnicity and social background (TEF, 2016).

Results of the 2017 TEF were released in June 2017 (www.hefce.ac.uk). According to the announcement, $231 \mathrm{UK}$ universities and other higher education institutions were awarded Gold, Silver or Bronze ratings for the quality of their teaching at the undergraduate level. In particular, just over $25 \%$ higher education providers were rated gold, about $50 \%$ silver and just under $25 \%$ bronze. Among those in the top category were eight Russel Group institutions, corresponding to $38 \%$ of all Russel universities.

Along with aiming to boost the quality of teaching, a main driver of the TEF is to provide all current and prospective stakeholders, notably future undergraduate applicants, with more -and more meaningful- information, so that they can make an informed choice about where to pursue an undergraduate degree ${ }^{1}$. Thus, TEF rating gives universities the opportunity to provide market signals in the education market.

Among the Russell Group universities - traditionally seen to be the best in the UK eight out of 21 institutions were awarded the Gold rating, including Oxford, Cambridge, Birmingham, Leeds, Nottingham, and Exeter, while 10 institutions got Silver, including Manchester. The London School of Economics was awarded the lowest bronze rating, as did Liverpool, Southampton, Goldsmiths and the School of Oriental and African Studies (SOAS). All of these universities were outperformed in the TEF by newer universities such as Liverpool Hope and Lincoln, along with small specialist institutions, such as The Royal Veterinary College and Royal Northern College of Music, which received Gold rating.

To the best of our knowledge, there has been no study to this day on the degree of accomplishment of the TEF as an instrument that allows prospective students to make an informed choice about the university they will attend. This study aims to fill this gap. For this purpose, we set out to examine two hypotheses. First, we investigate whether there is countersignaling, that is whether top-ranked higher education institutions are least likely to disclose their TEF rating. Second, we examine whether Guardian rankings are consistent and informative about university TEF results.

\footnotetext{
${ }^{1}$ It is noted that TEF results are not broken down by subject areas. A university receives one TEF rating for the entire institution.
} 


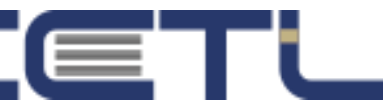

International Conference on Research in Education, Teaching and Learning

Paris, France| November 2-4, 2018

In line with prior literature, we find that the higher the ranking of the university the less the likelihood to disclose the TEF result on the university's website. Thus, we assert that universities that have a higher rank use nondisclosure as a countersignal, while universities that have a middle rank use disclosure to stand out from the other middle rank universities. Moreover, we find that the probability of UK universities to get a TEF Gold is significantly lower than that of the top-10 and that probability falls substantially in lower ranking buckets. In addition, even though Guardian rankings appear to be generally consistent with and supportive of TEF ratings, only $35 \%$ of the top ranked universities by The Guardian are rated TEF Gold, indicating inconsistency between Guardian rankings and public national TEF classifications. Although this finding may be related to the fact that rankings place higher weight on researchrelated criteria than teaching, further investigation would be necessary, so as to improve the "product" information available to prospective students via university rankings.

The remaining of the paper is structured as follows. Section 2 presents a review of related literature. In the third section we lay out the hypotheses. Our sample and methodology are presented in Section 4. Presentation and discussion of our empirical findings is given is Section 5. Concluding remarks and suggestions for further research are outlined in Section 6.

\section{Literature Review}

According to mainstream economic theory, mandatory disclosure of quality information is not necessary because market mechanisms will lead all suppliers, except the poorest quality, to voluntarily disclose, assuming consumer rationality and negligible disclosure costs (see, for example, Grossman, 1981; Milgrom, 1981; Jovanovic, 1982). As Milgrom (1981) puts it, the supplier reports the most favorable data about the product and the buyer takes a skeptical view of any information the supplier does not reveal. Thus, if consumers are rational, suppliers are better off by disclosing information.

It has also been shown that mandatory disclosure rules are not necessarily welfare improving, suggesting that the role of the government is limited to facilitating voluntary disclosure (Easterbrook and Fishcel, 1984; Fishman and Hagerty, 2003). There are, however, empirical studies on disclosure that find evidence that market unravelling is incomplete (Jin, 2005; Bederson et al., 201X).

A large number of studies show that where students apply greatly affects their future income, pointing to a high return to institution quality (Zhang 2005, Black and Smith 2006). Even studies that do not find evidence in favor of return to students selecting to pursue undergraduate studies in a good quality institution, there are studies that attest to the fact that selectivity yields significant returns in the case of disadvantaged students (Dale and Krueger, 2002).

In a variety of economic sectors, from healthcare (see for example, Jin, 2005; Jung, 2010) to shipping (see, for example, Andrikopoulos et al., 2013) and from 


\section{ETL}

International Conference on Research in Education, Teaching and Learning

Paris, France| November 2-4, 2018

manufacturing (see for example, Matherly and Burton, 2005) to banking (see, for example, Estrella, 2004), researchers have depicted website disclosure as a main driver of performance. Similarly, internet disclosure has attracted the interest of researchers who focus on the behavior of higher education institutions. Website disclosure has been investigated primarily in the form of signaling for strategic purposes (Feltovich et al., 2002; Luca and Smith, 2015). A strand of research has concentrated on the quality of information that is generally revealed in the websites (Michelon et al. 2015).

Feltovich et al. (2002) define countersignaling as taking place when a high-quality firm signals high quality through non-disclosure. In a job interview example, with job candidates of high, medium, or low ability, the candidates may signal their ability through an endogenous signal (sharing their GPAs) and an exogenous signal (a recommendation letter). On the one hand, high and medium types have good GPAs while the low type has bad GPAs. Thus GPAs separate high and medium from low, but not high from medium. On the other hand, a recommendation letter is always good for high ability candidates, always bad for low-ability candidates, but can be good or bad for the medium-ability candidates. Hence, the recommendation letter is still not enough to distinguish the high type from the medium ability candidates. Thus, the authors argue that countersignaling can help to separate all three types if the high type do not disclose their high GPAs, because this countersignaling action plus the favorable recommendation letter may help them stand out from the medium candidates that disclose high GPAs and have a good letter. In contrast, medium-ability high-GPA candidates cannot afford to hide their high GPAs because they do not know the exact content of the recommendation letter when they make the disclosure decision and high GPAs will clearly distinguish them from the low-ability candidates even if the letter turns out bad.

The work of Luca and Smith (2015) focuses on the quality of information posted on higher education institutions websites. The authors look at the general case of the former on the impact of types of information disclosed on accountability and in the case of the latter in applicant's decisions to enroll in a higher education institution. Analyzing the disclosure decisions of $240 \mathrm{MBA}$ programs about which rankings to display on their websites, they confirm that top schools are least likely to disclose their rankings, whereas mid-ranked schools are most likely to disclose. The authors also find that schools treat rankings by different reviewers as substitutes and generally tend to coarsen information to make it seem more favorable.

In an earlier study, Luca and Smith (2013) investigate the impact of college rankings on students' application decisions in the U.S., depicting a causal impact of rankings on application decisions, with a one-rank improvement leading to a one per cent increase in the number of applications. Moreover, the authors assert the role of information as a salient determinant of demand in the U.S. education market. In the same spirit, Opoku et al. (2006) identify a variety of brand personality features that relate to MBA 


\section{ETL}

International Conference on Research in Education, Teaching and Learning

Paris, France| November 2-4, 2018

offering higher education institutions in South Africa, arguing that brand personality portrayed in the university website will positively influence the various stakeholders of each Business School.

Finally, Dranove and Jin (2010), who review empirical evidence on quality disclosure in the sectors of healthcare, education, and finance argue that although there are many examples in which quality disclosure has benefitted consumers by allowing them to find suppliers who best meet their needs, there is less evidence that that suppliers respond by boosting quality. The authors present evidence indicating that suppliers responses in the three sectors examined often focus on gaming behavior that harms consumers, on top of measurement errors, consumer misunderstandings and inspector bias that are also to the consumer's detriment. In the long-run, however, Dranove and Jin (2010) argue that quality disclosure drives out low quality firms, invites high quality competitors and/or encourages existing firms to improve quality, thus benefitting consumers.

\section{Hypotheses}

Based on prior research in the field of disclosure in general and disclosure practices in higher education in particular, we test three hypotheses as follows:

H1

Is there countersignaling in UK higher education, namely are top-rated UK universities least likely to disclose their TEF rating?

In a variety of economic settings, top-quality suppliers tend to eschew disclosing signals that separate them from low-quality suppliers. For example, Fremling and Posner (1999) argue that high status suppliers may have lower marginal returns from signaling than those who are ranked lower. Moreover, Feltovich et al. (2002) show that "high types" not only save the costs by relying on the additional information that separates them from "low types", but also countersignaling constitutes a signal of confidence that separates "high types" from "medium types". Thus, our first hypothesis relates to the practice of countersignaling in university education. Based on the literature, we expect that top-rated UK universities to be least likely to disclose their TEF rating, affirming the practice of countersignaling in UK higher education.

$\mathrm{H} 2$

Are the Guardian rankings consistent with and informative about TEF ratings?

Before the establishment of the Teaching Excellence Framework, university rankings were mostly based on research-related criteria, overemphasizing research performance and neglecting teaching and activities enhancing student engagement. University rankings have been severely criticized for that, as well as for being based on unreliable data (Bekhradnia, 2016). Moreover, there is a perception that prospective students rely more on word of mouth than official rankings for their choice of 


\section{ETL}

International Conference on Research in Education, Teaching and Learning

Paris, France| November 2-4, 2018

university (Milian and Rizk, 2017). We expect Guardian rankings to be consistent with and informative about TEF ratings.

\section{H3}

Do universities that are being ranked by different sources practice selective disclosure?

University ranking systems aspire to offer information about the quality of education provided by higher education institutions. Usually, there are more than one sources that provide rankings for universities. In some cases rankings differ, being more attractive to disclose in the case of lower ranked institutions. Dill et al. (2005) confirm both differences and similarities amongst the particular measures each different ranking system adopts. Some measures include university reputation as, for example, that of The Guardian. To test whether universities practice selective disclosure, we analyze web disclosure on the basis of rankings in three categories: (a) overall rank, (b) source-only, and (c) specialty rank. We expect that universities that voluntarily disclose their ranking practice selective disclosure.

\section{H4}

\section{Is Guardian ranking related to university funding through tuition fees and research grants?}

As university ranking constitutes an important input in the decision where to study, university ranking could be a factor influencing university pricing policy. Indeed, although tuition is not found to be elastic to ranking in the pertinent literature, there is evidence that institutions of lower rank tend to decrease net tuition in order to attract more students, for example through price discounts and student aid (Monks and Ehrenberg, 1999). Moreover, research funding is typically a function of the results of the evaluation of university research output performed by governmental bodies (Hicks, 2012). However, it is a fact that research grant funds traditionally tend to concentrate in top-ranked universities across both sides of the Atlantic (see, for example, Hezelkorn, 2013; Myklebust, 2012). Based on the above, we expect university funding through grants and tuition fees to be directly related to Guardian ranking.

\section{Sample description and methodology}

Our sample consists of 121 universities, all of them ranked by The Guardian for the year 2017 where TEF (Teaching Excellence Framework) rating was first publicly undertaken by an independent State agency. This number accounts for roughly $92.5 \%$ of the entire UK university population. For the remaining 10 universities taking part in the national survey, we had no rankings by The Guardian. All data were retrieved from Guardian rankings and the published TEF results. Further, we derived from the web sites of all 121 universities included in our sample ranking disclosure by category. In addition, we derived manually from the annual accounts of each 


\section{ETL}

International Conference on Research in Education, Teaching and Learning

Paris, France| November 2-4, 2018

university included in our sample funding information, total and by category, for the year 2016-2017.

Our relationships of interest are specified below:

TEFG=f(C, R1, R2, R3, R4)

TEFS $=z(C, R 1, R 2, R 3, R 4)$

$\mathrm{TEFB}=\mathrm{y}(\mathrm{C}, \mathrm{R} 1, \mathrm{R} 2, \mathrm{R3}, \mathrm{R4}, \mathrm{UNR})$

All our variables are binary assuming the value of 1 if their definition holds and 0 otherwise. We use the linear probability model (Probit) for estimation purposes. The omitted variable c, includes the top-10 universities, over all subjects, as ranked by The Guardian. Table 1 gives the definitions of dependent and independent variables in our model.

Table 1. Definition of dependent and independent variables

\begin{tabular}{|ll|}
\hline \multicolumn{2}{|l|}{ Dependent variables } \\
\hline TEFG $\quad$ Universities ranked as Gold in the TEF survey \\
\hline TEFS & Universities ranked as Silver in the TEF survey \\
\hline TEFB & Universities ranked as Silver in the TEF survey \\
\hline Independent variables \\
\hline R1 & Universities ranked 11-29 by The Guardian \\
\hline R2 & Universities ranked 21-50 by The Guardian \\
\hline R3 & Universities ranked 51-80 by The Guardian \\
\hline R4 & Universities ranked $81-121$ by The Guardian \\
\hline UNR & Universities unranked by The Guardian \\
\hline
\end{tabular}

\section{Empirical Findings and Discussion}

With regard to our first hypothesis, $\mathrm{H} 1$, the results presented in Figure 1 are consistent with countersignaling practiced by top universities as ranked by The Guardian. That is, the top universities are least likely to disclose their TEF result, even if this is Gold. More specifically, out of the 121 universities that got TEF classification in the three categories, namely Gold, Silver and Bronze, it appears that:

$>$ Only 39 disclosed voluntarily their ranking on their websites (32\% of the total)

$>$ Out of these 39 universities, only 12 or $31 \%$ disclosed TEFGOLD and these universities where other than those classified by The Guardian in the top 10

$>20$ out of 39 universities, or $51 \%$, disclosed on the web their TEFSILVER classification

Only 7 out of 39, or $18 \%$, disclosed their TEFBRONZE classification.

It appears, therefore, that the top-rated universities in terms of teaching excellence do not disclose their ranking, while middle-rated universities are most likely to disclose their TEF rating. 
International Conference on Research in Education, Teaching and Learning

Paris, France| November 2-4, 2018

Figure 1. Voluntary Disclosure by TEF category

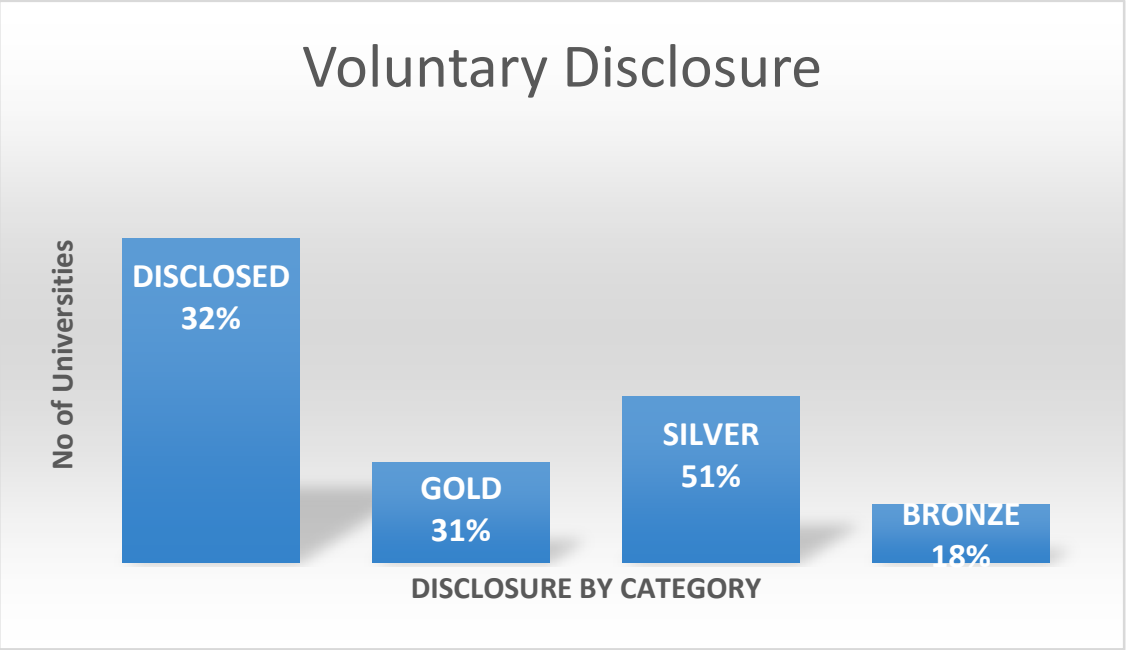

Next, we investigate the hypothesis that Guardian rankings are consistent with TEF ratings. For this we run three regressions, one for each category of TEF rating.

Table 2 indicates that the probability that a university from R1 (11-29 in Guardian rankings) will get a TEFGOLD is $69 \%$ lower compared to a university ranked by The Guardian in the top 10. Second, the probability that a university from R2 (21-50 in Guardian rankings) will get a TEFGOLD is $69 \%$ lower compared to a university ranked by The Guardian in the top 10 . Third, the probability that a university from R3 (51-80 in Guardian rankings) will get a TEFGOLD is $97 \%$ lower compared to a university ranked by The Guardian in the top 10. Finally, the probability that a university from R4 (81-121 in Guardian rankings) will get a TEFGOLD is $180 \%$ lower compared to a university ranked by The Guardian in the top 10.

All variables in the model presented in Table 2 have the expected signs.

\begin{tabular}{|c|c|}
\hline Dependent variable: & TEFGOLD \\
\hline & Coefficient \\
\hline \multirow[t]{2}{*}{ Constant } & 0.349 \\
\hline & $(0.051)^{* * *}$ \\
\hline \multirow[t]{2}{*}{$\mathrm{R} 1$} & -0.699 \\
\hline & $(0.411)^{*}$ \\
\hline \multirow[t]{2}{*}{$\mathrm{R} 2$} & -0.698 \\
\hline & $(0.394)^{*}$ \\
\hline \multirow[t]{2}{*}{$\mathrm{R} 3$} & -0.972 \\
\hline & $(0.428) * * *$ \\
\hline \multirow[t]{2}{*}{$\mathrm{R} 4$} & -1.802 \\
\hline & $(0.457)^{* * *}$ \\
\hline UNR & - \\
\hline
\end{tabular}




\section{压ᄂ}

International Conference on Research in Education, Teaching and Learning

Paris, France| November 2-4, 2018

The estimated model improves on the Dep $=1$ predictions by 20 percentage points, but does more poorly on the Dep $=0$ predictions ( -4.40 percentage points). Overall, the estimated equation is 6.67 percentage points better at predicting responses than the constant probability model.

Success cutoff: $\mathrm{C}=0.5$

\begin{tabular}{|c|c|c|c|c|c|c|}
\hline & \multicolumn{3}{|c|}{ Estimated Equation } & \multicolumn{3}{|c|}{ Constant Probability } \\
\hline & Dep $=0$ & Dep $=1$ & Total & Dep $=0$ & Dep $=1$ & Total \\
\hline $\mathrm{P}(\mathrm{Dep}=1)<=\mathrm{C}$ & 87 & 24 & 111 & 91 & 30 & 121 \\
\hline $\mathrm{P}(\mathrm{Dep}=1)>\mathrm{C}$ & 4 & 6 & 10 & 0 & 0 & 0 \\
\hline Total & 91 & 30 & 121 & 91 & 30 & 121 \\
\hline Correct & 87 & 6 & 93 & 91 & 0 & 91 \\
\hline$\%$ Correct & 95.60 & 20.00 & 76.86 & 100.00 & 0.00 & 75.21 \\
\hline$\%$ Incorrect & 4.40 & 80.00 & 23.14 & 0.00 & 100.00 & 24.79 \\
\hline Total Gain* & -4.40 & 20.00 & 1.65 & & & \\
\hline \multirow[t]{3}{*}{ Percent Gain** } & NA & 20.00 & 6.67 & & & \\
\hline & \multicolumn{3}{|c|}{ Estimated Equation } & \multicolumn{3}{|c|}{ Constant Probability } \\
\hline & Dep $=0$ & Dep $=1$ & Total & Dep $=0$ & Dep $=1$ & Total \\
\hline $\mathrm{E}(\#$ of Dep=0) & 71.72 & 19.32 & 91.04 & 68.44 & 22.56 & 91.00 \\
\hline $\mathrm{E}(\#$ of Dep=1) & 19.28 & 10.68 & 29.96 & 22.56 & 7.44 & 30.00 \\
\hline Total & 91.00 & 30.00 & 121.00 & 91.00 & 30.00 & 121.00 \\
\hline Correct & 71.72 & 10.68 & 82.40 & 68.44 & 7.44 & 75.88 \\
\hline$\%$ Correct & 78.82 & 35.60 & 68.10 & 75.21 & 24.79 & 62.71 \\
\hline$\%$ Incorrect & 21.18 & 64.40 & 31.90 & 24.79 & 75.21 & 37.29 \\
\hline Total Gain* & 3.61 & 10.81 & 5.40 & & & \\
\hline Percent Gain** & 14.56 & 14.37 & 14.47 & & & \\
\hline
\end{tabular}

Table 3 illustrates that it is highly unlikely for top-ranked universities to get a TEFSILVER (probability -0.84). The highest probability compared to top-ranked to be given TEFSILVER is assumed by $\mathrm{R} 3$ universities in the Guardian ranking. 
International Conference on Research in Education, Teaching and Learning

Paris, France| November 2-4, 2018

Table 3

Dependent variable:

TEFSILVER

\begin{tabular}{|lc|}
\hline & Coefficient \\
\hline Constant & 0.836 \\
\hline & $(0.369)^{* * *}$ \\
\hline R1 & 0.577 \\
\hline R2 & $(0.388)^{*}$ \\
\hline & 0.403 \\
\hline R3 & $(0.392)$ \\
\hline & 0.919 \\
\hline R4 & $(0.434)^{* * *}$ \\
\hline & 0.682 \\
\hline UNR & $(0.418)^{* *}$ \\
\hline
\end{tabular}

$* * *$ Significant at the $1 \%$ level, *Significant at the $10 \%$ level, $* *$ Significant at the $5 \%$ level

The estimated model of Table 3 improves on the Dep $=1$ predictions by 40.38 percentage points, but does more poorly on the Dep $=0$ predictions $(-26.09$ percentage points). Overall, the estimated equation is 5.77 percentage points better at predicting responses than the constant probability model.

Success cutoff: $\mathrm{C}=0.5$

\begin{tabular}{|c|c|c|c|c|c|c|}
\hline & \multicolumn{3}{|c|}{ Estimated Equation } & \multicolumn{3}{|c|}{ Constant Probability } \\
\hline & Dep $=0$ & Dep $=1$ & Total & Dep $=0$ & Dep=1 & Total \\
\hline $\mathrm{P}(\mathrm{Dep}=1)<=\mathrm{C}$ & 51 & 31 & 82 & 69 & 52 & 121 \\
\hline$P(\operatorname{Dep}=1)>C$ & 18 & 21 & 39 & 0 & 0 & 0 \\
\hline Total & 69 & 52 & 121 & 69 & 52 & 121 \\
\hline Correct & 51 & 21 & 72 & 69 & 0 & 69 \\
\hline$\%$ Correct & 73.91 & 40.38 & 59.50 & 100.00 & 0.00 & 57.02 \\
\hline$\%$ Incorrect & 26.09 & 59.62 & 40.50 & 0.00 & 100.00 & 42.98 \\
\hline Total Gain* & -26.09 & 40.38 & 2.48 & & & \\
\hline \multirow[t]{3}{*}{ Percent Gain** } & NA & 40.38 & 5.77 & & & \\
\hline & \multicolumn{3}{|c|}{ Estimated Equation } & \multicolumn{3}{|c|}{ Constant Probability } \\
\hline & Dep $=0$ & Dep $=1$ & Total & Dep $=0$ & Dep $=1$ & Total \\
\hline $\mathrm{E}(\#$ of $\mathrm{Dep}=0)$ & 40.55 & 28.45 & 69.00 & 39.35 & 29.65 & 69.00 \\
\hline $\mathrm{E}(\#$ of $\mathrm{Dep}=1)$ & 28.45 & 23.55 & 52.00 & 29.65 & 22.35 & 52.00 \\
\hline Total & 69.00 & 52.00 & 121.00 & 69.00 & 52.00 & 121.00 \\
\hline Correct & 40.55 & 23.55 & 64.10 & 39.35 & 22.35 & 61.69 \\
\hline$\%$ Correct & 58.77 & 45.28 & 52.97 & 57.02 & 42.98 & 50.99 \\
\hline$\%$ Incorrect & 41.23 & 54.72 & 47.03 & 42.98 & 57.02 & 49.01 \\
\hline Total Gain* & 1.74 & 2.31 & 1.98 & & & \\
\hline Percent Gain** & 4.05 & 4.05 & 4.05 & & & \\
\hline
\end{tabular}


Moving on to Table 4, it is evident that only $\mathrm{R} 4$ universities have a significant probability, albeit low (14\%), to be given TEFBRONZE. The table indicates that only universities ranked under R4 and those that are unranked impact significantly on TEFBRONZE ratings, being significant at the $10 \%$ level.

Table 4

\begin{tabular}{|lc|}
\hline Dependent variable: & TEFBRONZE \\
\hline & Coefficient \\
\hline Constant & 0.061 \\
\hline & $(0.076)$ \\
\hline R1 & 0.015 \\
\hline R2 & $(0.084)$ \\
\hline & 0.006 \\
\hline R3 & $(0.008)$ \\
\hline & 0.018 \\
\hline R4 & $(0.092)$ \\
\hline & 0.144 \\
\hline UNR & $(0.088)^{*}$ \\
\hline & -0.128 \\
\hline
\end{tabular}

*Significant at the $10 \%$ level, ${ }^{* *}$ Significant at the $5 \%$ level

Even though Guardian rankings appear to be generally consistent and supportive of the TEF classifications, it must be pointed out that the relationship in Table 2, shows through the coefficient of the constant term that only 35\% of the top ranked universities by The Guardian, are classified as TEFGOLD. Although at first glance this may seem to be attributable to a traditional over-emphasis on university research performance at the expense of teaching, further investigation on the consistency between Guardian rankings and national TEF classifications might be needed before concluding that university rankings are useful in helping student consumers to make an informed choice about where to study.

Figure 2 depicts selective disclosure practices, thus addressing our third hypothesis, H3. The pie-chart illustrates that

$>$ Only $41 \%$ of the ranked universities disclose their ranking

$>16 \%$ of those disclose the overall rank

$>34 \%$ disclose source only

$>36 \%$ disclose their specialty rank

Thus, the majority of the universities that voluntarily disclose their ranking practice selective disclosure. Of those, about $70 \%$ disclose either specialty ranking or their ranking according to a specific source. 


\section{ETL}

International Conference on Research in Education, Teaching and Learning

Paris, France| November 2-4, 2018

Figure 2

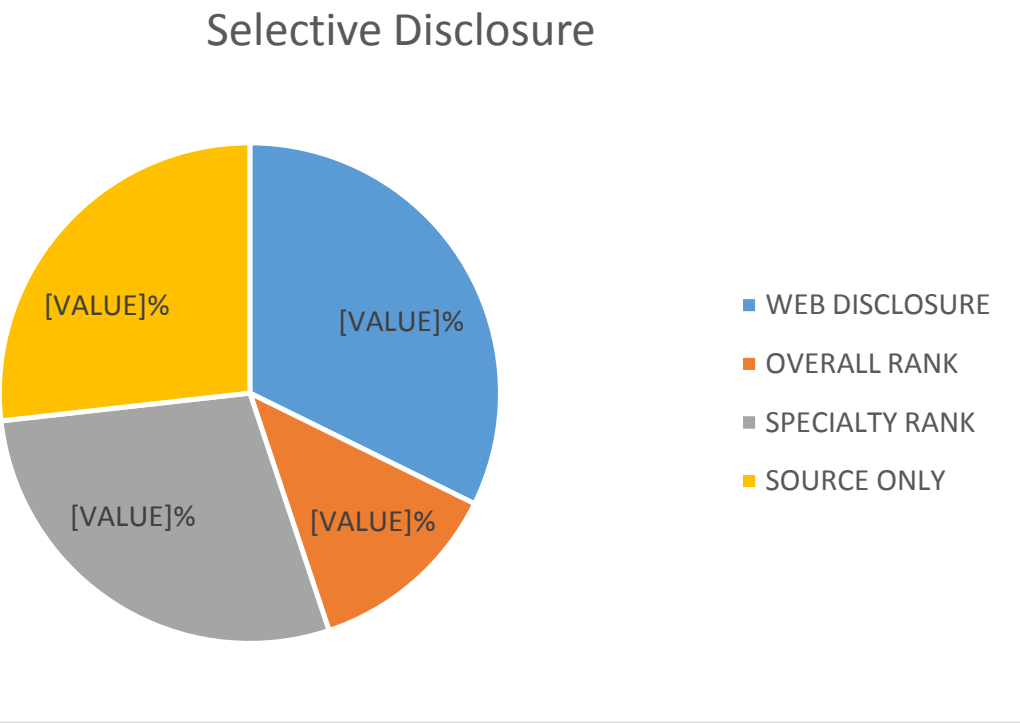

Table 5

Dependent Variable: SOURCE_ONLY

\begin{tabular}{rrlrr}
\hline \hline \multicolumn{1}{c}{ Variable } & Coefficient & \multicolumn{1}{c}{ Std. Error } & Z-Statistic & Prob. \\
\hline C & -1.297403 & 0.423366 & -3.064496 & 0.0022 \\
R1 & 0.037359 & 0.429260 & 0.087031 & 0.9306 \\
R2 & 0.761125 & 0.453522 & 1.678252 & 0.0933 \\
\multicolumn{1}{c}{ R4 } & 1.067519 & 0.502021 & 2.126444 & 0.0335 \\
& 0.731454 & 0.463991 & 1.576441 & 0.1149 \\
\hline \hline & & & & \\
McFadden R-squared & 0.039491 & Mean dependent var & & 0.280992 \\
S.D. dependent var & 0.451352 & S.E. of regression & & 0.449125 \\
Akaike info criterion & 1.223514 & Sum squared resid & & 23.39875 \\
Schwarz criterion & 1.339042 & Log likelihood & & -69.02259 \\
Hannan-Quinn criter. & 1.270434 & Deviance & & 138.0452 \\
Restr. deviance & 143.7208 & Restr. log likelihood & & -71.86039 \\
LR statistic & 5.675611 & Avg. log likelihood & & -0.570435 \\
Prob(LR statistic) & 0.224719 & & & \\
\hline \hline
\end{tabular}

Obs with Dep $=0$

87 Total obs

121

Obs with Dep $=1$ 


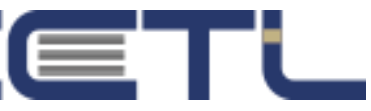

International Conference on Research in Education, Teaching and Learning

Paris, France| November 2-4, 2018

Table 5 gives further evidence that selective disclosure tends to be practiced by universities which are ranked by The Guardian $22^{\text {nd }}$ to $121^{\text {st }}$ place, i.e. R2, R3, and $\mathrm{R} 4$, as indicated by the values of the coefficients of these variables.

Finally, with reference to our fourth hypothesis, H4, Table 6 indicates that when the number of students and grants rise the probability for the university to be ranked in 110 (R0) rises. When the number of students and grants rise the probability for the university to be ranked 11-20(R1) rises. Similarly, for the case of R2. For R3 and R4, as grants and the number of students rise the probability to be ranked 51-121 falls.

Table 6

\begin{tabular}{|l|l|l|l|l|l|}
\hline & $\mathrm{R} 0$ & $\mathrm{R} 1$ & $\mathrm{R} 2$ & $\mathrm{R} 3$ & $\mathrm{R} 4$ \\
\hline Constant & -4.224 & -4.416 & -2.454 & 0.765 & 3.255 \\
& $(0.961)^{* * *}$ & $(1.28)^{* * *}$ & $(0.830)^{* * *}$ & $(0.812)$ & $(0.907)^{* * *}$ \\
& 0.258 & 0.438 & 0.173 & -0.276 & -0.532 \\
\hline $\log$ (tuition) & $(0.179)^{*}$ & $(0.266) *$ & $(0.188)$ & $(0.208)$ & $(0.228)^{* * *}$ \\
\hline $\log$ (grants) & 0.440 & 0.369 & 0.287 & -0.128 & -0.408 \\
& $(0.146)^{* * *}$ & $(0.168)^{* * *}$ & $(0.137) * *$ & $(0.140)$ & $(0.147)^{* * *}$ \\
\hline
\end{tabular}

Overall, our results indicate that even though Guardian university rankings are consistent with TEF ratings, top universities practice countersignaling. Those universities that disclose results practice selective disclosure and their rankings are highly correlated with grants and tuition revenues.

\section{Conclusion}

The Teaching Excellence Framework recently implemented in the UK higher education sector has reputational consequences for UK universities as publication of the TEF results and incorporation of these results in university rankings may impact student recruitment both at the national and the international levels. The purpose of this paper has been to investigate whether there is countersignaling in disclosure of UK higher education institutions, that is whether top-ranked UK universities are least likely to disclose their TEF rating. Moreover, we examined whether The Guardian rankings are consistent and informative about the university TEF ratings announced in June 2017.

Thus, we categorize UK universities in five buckets on the basis of their ranking and investigate whether top ranked schools are least likely to disclose their rankings on their websites. Furthermore, we test whether Guardian university rankings are consistent and informative about the TEF medals awarded. Our finding that the higher the ranking of the university the less the likelihood to disclose the TEF result on the university's website is consistent with prior literature.

We assert that universities that have a higher rank use nondisclosure as a countersignal, while universities that have a middle rank use disclosure to stand out from the other middle rank universities. Moreover, we find that the probability of UK 


\section{ETL}

International Conference on Research in Education, Teaching and Learning

Paris, France| November 2-4, 2018

universities to get a TEF Gold is significantly lower than that of the top-10 and that probability falls substantially in lower ranking buckets.

Finally, even though Guardian rankings appear to be generally consistent with and supportive of TEF ratings, only $35 \%$ of the top-ranked universities by The Guardian are rated TEF Gold, indicating discrepancy between Guardian rankings and public national TEF classifications, thereby rendering further investigation of the Guardian ranking - TEF rating relationship necessary, in order to enhance the usefulness of rankings for student consumers.

\section{References}

Andrikopoulos, A., Merika, A., Triantafyllou and A., Merikas, A.: Internet Disclosure and Corporate Performance: A Case Study of the International Shipping Industry, Transportation Research Part A, 47, 141-152, 2013

Becker G.S.: Human Capital, Columbia University Press, 1964

Bederson, B.B., Jin, G., Leslie, P., Quinn A.J. and Zou, B.: Incomplete Disclosure: Evidence of Signaling and Countersignaling, NBER Working Paper No. 22710, 2016

Bekhradnia, B.: International University Rankings: For good or ill?, Higher Education Policy Institute Report 89, 2016

Dill, D. and Soo, M.: Academic Quality, League Tables, and Public Policy: A CrossNational Analysis Of University Ranking Systems, Higher Education, 49, 495-533, 2005

Dranove, D. and Jin, G.Z.: Quality Disclosure and Certification, Journal of Economic Literature, 48(4), 935-963, 2010

Estrella, A.: Bank Capital and Risk: Is Voluntary Disclosure Enough?, Journal of Financial Services Research, 26(2), 145-160, 2004

Feltovich, N., Harbaugh, R. and To, T.: Too cool for School? Signaling and countersignaling, Rand Journal of Economics, 33(4), 630-649, 2002

Grossman, S. J.: The Informational Role of Warranties and Private Disclosure about Product Quality, The Journal of Law and Economics, 24(3), 461-483, 2002

Hazelkorn, E. and Ryan, M.: The Impact of University Rankings on HigherEducation Policy in Europe: A Challenge to Perceived Wisdom and a Stimulus for Change, in Zgaga, P., Teichler, U. and Brennan, J. (eds.): The Globalization Challenge for European Higher Education: Convergence and Diversity, Centres and Peripheries. Frankfurt, Peter Lang, 2013

Hicks, D.: Performance-Based University Research Funding Systems, Research Policy, 41, 251-261, 2012

Jin, G.Z.: Competition and Disclosure Incentives: an Empirical Study of HMOs, Rand Journal of Economics, 36(1), 93-112, 2005

Jovanovic, B.: Truthful Disclosure of Information, Bell Journal of Economics, Vol. 13, 3644, 1982

Jung. K., Incentives for Voluntary Disclosure of Quality Information in HMO Markets, The Journal of Risk and Insurance, 77(1), 183-210, 2010

Luca, M. and Smith, J.: Salience in the Quality of Disclosure: Evidence from the U.S. News College Rankings, Journal of Economics and Management Strategy, 22(1), 58-77, 2013 


\section{ETL}

International Conference on Research in Education, Teaching and Learning

Paris, France| November 2-4, 2018

Luca, M. and Smith, J.: Strategic Disclosure: The Case of Business Schools Rankings, Journal of Economic Behavior and Organization, 112, 17-25, 2015

Matherly, C.M. and Burton, H.A.: An Analysis of Corporate Website Disclosures, Management Accounting Quarterly, 6 (2), 26-33, 2005

Michelon, G., Pilonato, S. and Ricceri, F.: CSR Reporting Practices and the Quality of Disclosure: An Empirical Analysis, Critical Perspectives on Accounting, 33, 59-78, 2015

Milgrom, P.R.: Good news and bad news: representation theorems and applications, Bell Journal of Economics, 12, 380-391, 1981

Millian, R.P. and Rizk, J.: Do university rankings matter? A Qualitative Exploration of Institutional Selection at Three Southern Ontario Universities, Journal of Further and Higher Education, https://doi.org/10.1080/0309877X.2017.1349889, 2017

Monks, J. and Ehrenberg, R.G: The Impact of U.S. News \& World Report College Rankings on Admissions Outcomes and Pricing Policies at Selective Private Institutions, NBER Working Paper, No 7227, 1999

Myklebust, J. P.: ERC Defends Concentration of Grants in Top Research Universities, World University News, http://www.universityworldnews.com/article.php?story=20120308181711918

Opoku, R., Abratt, R. and Pitt, L.: Communicating Brand Personality: Are the Websites Doing the Talking for the Top South African Business Schools?, Brand Management, 14 (1/2), 20-39, 2006

Pallais, A.: Small Differences that Matter: Mistakes in Applying to College, Journal of Labour Economics, 33(2), 493-520, 2015

Teaching Excellence Framework: Technical Consultation for Year Two, UK Department of Business Innovation and Skills, 2016. 